\title{
Conversational Styles and Misunderstanding in Cross-Sex Conversations in He's Just Not That into You Movie
}

\author{
Ayu Nyoman Aryani \\ Sanata Dharma University
}

\begin{abstract}
Conversation is a social interaction among societies. In this case, gender differences in daily communication lead to men's and women's different point of views in performing styles of the conversations. Misunderstanding is likely to occur in crosssex conversations when the idea or thought are understood differently by men and women. This study was intended to analyze the use of conversational styles by men and women and also investigate the misunderstanding phenomena that happened in cross-sex conversations. The researcher identified that the conversational styles used by Alex as a male character in the cross-sex conversations were qualifiers, controlling the topics, verbal fillers, intensifiers, swear words, compound requests, tag questions, questions, interruptions, overlapping, and talk domination. Meanwhile, Gigi, as a female character used qualifiers, controlling the topics, verbal fillers, intensifiers, swear words, tag questions, questions, interruptions, overlapping, talk domination, and silence. In answering the second question, the researcher discovered factors that affected the misunderstanding in the cross-sex conversations between Alex and Gigi were involvement versus independence and message versus metamessage.
\end{abstract}

Keywords: conversational styles, cross-sex conversations, misunderstanding, He's Just Not That into You movie

\section{Introduction}

Language and gender are two different things which cannot be separated from our communication in social life. According to Wardhaugh (2010), "gender is a key component of identity" where it becomes a part of the way in which societies are doing interaction (p. 334). Both men and women have different styles for their friendly conversations. They have their own ways and perceptions when talking to each other. In this case, misunderstanding is likely to occur in a cross-sex conversation since both men and women have different rules in their conversations. Tsutsui (2008) argues that there will be a possibility to be understood differently by others when we express our thoughts or ideas. For 
those points of view, this study would like to analyze the misunderstanding phenomenon with the use of language in cross-sex conversations. There are two formulated questions. First, which conversational styles are used by Alex and Gigi in He's Just Not That into You movie? Second, what factors affect the misunderstanding in their conversations (cross- sex conversations)?

By using an American movie entitled He's Just Not That into You, the researcher analyzed the main character, Alex and Gigi as the subject of this study. To answer the first and the second research questions, the researcher conducted discourse analysis in which Alex and Gigi's conversations was analyzed. For the first research question, the researcher identified which conversational styles that were used by Alex and Gigi in their conversations. For the second research question, the researcher investigated the factors that made Alex and Gigi to get misunderstanding when they were talking to each other.

\section{Theoretical Ground}

\section{Conversational Styles}

The conversational styles are the way of how people express their utterance. Every person, especially in different genders, has different characteristics in sharing what they really want to talk about. Tannen (1995) mentions that "aspects of conversational style are the basic tools of talk - the way we show what we mean when we say (or don't say) something." Lakoff (1973) reveals that the way of men and women using grammatical construction is clearly different. She states that men are more likely "straightforward" rather than women when they express their utterance grammatically (as cited in Arliss, 1991). It is also supported by Pearson (1985), who mentions that there are several conversational styles differences between men and women. Those are qualifiers, controlling the topic, verbal fillers, intensifiers, profanity, compound requests, tag questions, questioning, interruption, overlaps, talk domination, silence (p. 181).

\section{Qualifiers}

Qualifiers or "hedges" is used to soften the strength of a statement. Pearson (1985) defines that hedges "indicate some measure of uncertainty about the other person's response to it" (p. 186). For example, if a speaker clearly describes a best friend as "pretty", but adds "I think," then the utterance is weakened by the expression of uncertainty. Mostly women use more qualifiers rather than men when they construct their statements.

\section{Controlling the Topics}

Pearson (1985) claims when the speakers can define reality, they have the power to control the topic in a conversation (p. 194). In this case, speakers who can explain topics which related to our real life, they will easily control the topic. Haas and Sherman (1982) report that women tend to talk about topics related to 
personal matters and the things about daily life. On the other hand, men tend to talk about money, news, and everything about sports (pp. 453454).

\section{Verbal Fillers}

Pearson (1985) explains that verbal fillers are used when the speaker fills in a silence of their conversation. The words or phrases like right, okay, well, and you know are frequently used by women rather than men, especially in cross-sex conversations. Apparently, people tend to avoid silences when they are talking, that is why they use it ( $p$. 186).

\section{Intensifiers}

Arliss (1991) states the use of intensifier is concerning with attention to the emotional message. In other words, intensifiers are adverbs such as so, such, quite, really, and awfully that are used to exaggerate the strength of a statement. For example, by adding the word so, on the sentence "I am so proud of you". The word so, that is used as an intensifier makes a speaker wants to emphasize his or her emotional message.

\section{Swear Words}

Swear words are commonly used by men and women in conversations. The speakers use them when they want to show their emotional expression to particular conditions around them. Lakoff (1975) notes that "men use stronger expletives (damn, shit) than women (oh dear, goodness).

\section{Compound Requests}

Generally, the speakers are using compound requests when they add words or phrases which soften the request. For example, when a speaker says Turn off the light, please rather than says Turn off the light! She or he tends to be more polite. In fact, Thorne and Henley (1975) mention that men are less frequently than women in using compound requests.

\section{Tag Questions}

Tag questions formulation is one of the grammatical constructions which are identified by Lakoff (1975), who mentions that tag question is used when the speaker is feeling unsure such as "You have a morning class today, don't you?" Moreover, Lakoff (1975) argues that women use tag question more often than men. They usually use it when addressing men.

\section{Questions}

Men and women use questions for different goals. Maltz and Borker (1982) assert that in order to maintain the conversation women use the questions more than man. In this case, they use the questions as speech act which needs an answer. Moreover, they state that the way of using questions by women are "their general strategy for conversational maintenance". Men, on the other hand, use more questions as a signal of asking for information. The difference of interpretation in using 
the questions can be one of the potential reasons for causing misunderstanding.

\section{Interruptions}

Zimmerman and West (1975) conclude that interruptions are considered as "violation of the turntaking rules of conversation". Furthermore, they explain that an interruption will occur when a second speaker begins to speak while a first speaker is still speaking and has not finished yet his or her last word which can be defined as the last statement. Pearson (1985) also argues that people interrupt because they believe that the message they want to offer is more important than the first speaker's message.

\section{Overlapping}

Pearson (1985) defines an overlap happens if the second speaker begins to speak at the ending point of the first speaker's turn which means the first speaker's last word. In addition, she describe that overlaps occur for the same reason as interruption: the second person believes that she or he proposes more important message (p. 198). On the other hand, the second speaker is very excited about talking.

\section{Factors of Misunderstanding in Cross-Sex Conversations}

The different ways of using conversational styles lead men and women to have different perceptions in understanding the meaning of communication. Tannen (1986) promotes some women and men differences in conversational styles.

\section{Talk Domination}

Basically, conversations are controlled by a speaker who is more powerful than the other. The powerful speaker means a speaker who is dominant in a conversation. Most of the popular opinions reveal that women are the one who talk more than men. Indeed, men talk more than women. This fact is asserted by Thorne (1981) where men are treated as "experts" in conversation. They are involved in more interactions than women (as cited in Pearson, 1985). In other words, Thorne's theory breaks the common opinion that actually men are the most powerful speaker in cross-sex conversation and they powerfully dominate the conversations.

\section{Silence}

Pearson (1985) states that women speakers tend to silence where they are not sure of the other speaker's reaction to their comment. More often, they explain that women speakers were silent more than men speakers in crossed-sex conversations (p. 198).

There are three factors of misunderstanding in cross-sex conversations as follows:

\section{Involvement versus Independence}

Tannen (1986) argues that involvement and independence are two different things which always 
arise in a conflict of communication itself. Women tend to stay for involvement where they can get a kind of intimacy in order to reach the goal of communication. For them, intimacy is about getting a connection where being understood without saying what they mean is the result on how they can get the involvement successfully. It is supported by Maltz and Borker (1982) where they reveal that women tend to see that conversations can be a kind of "therapeutic" for them. This means that they see an opportunity to share something like problems, experience, support, or even reassurance when they do the conversation.

According to Tannen (1986), men tend to stay for independence where they do not have to explain all of the things to their partner in communication, especially women. They think that get involved means no freedom at all in deciding something. Maltz and Borker (1982) also add that for men, sharing their personal problem is considered as not a normal conversation.

The problem appears when women are often unhappy with the reactions they get from men when they try to share their problem. On the other hand, men are often unhappy because they are accused of responding in the wrong way when they are trying to be helpful (Tannen, 1991, p. 28). In other words, when men and women talk to each other, the real problem is that each expects a different kind of response.

\section{Message versus Metamessage}

Tannen (1986) states that women are more listening to metamessage where it is about getting the understanding of what they have said explicitly in words. "Metamessages can be seen in what is not said as well as what is said" (p. 137). In contrast, men's style is more literally focused on the message level of talk. Men are more interested in utterances which sound to the point. In addition, they do not really catch the real meaning behind the message and the attitude from who they are talking to, especially to women. As a result, men and women have different point of views on almost any comment when they are interpreting the meaning of their conversations.

\section{Cooperative versus Competitive}

Tannen (1991) identifies that "girls like to play cooperatively" where they will establish and maintain the relation they have built by involving their friends to know their secret. This means that the way of talking the secret is more important than the secret itself. Conversely, boys like to play competitively where they will "maintain their own story and status" to be accepted as an equal for the others. Mostly they are talking about who is the best at what and it belongs to competitive talk (p. 143). 


\section{Discussion}

\section{The Conversational Style Used} by Alex and Gigi

To answer the first and the second research questions, the data were taken from He's Just Not That into You movie where the researcher transcribed Alex's and Gigi's spoken conversation into a written form. After that, the researcher made an observation checklist so that conversations could be analyzed easily.

Table 1 Frequency of Alex's and Gigi's Conversational Style

\begin{tabular}{|c|c|c|c|}
\hline \multirow{2}{*}{ No. } & \multirow{2}{*}{ Conversational Style } & \multicolumn{2}{|c|}{ Frequency } \\
\cline { 3 - 4 } & & Ale & Gigi \\
& & X & \\
\hline 1. & Qualifiers & 12 & 25 \\
\hline 2. & Controlling the Topics & 12 & 8 \\
\hline 3. & Verbal Fillers & 13 & 8 \\
\hline 4. & Intensifiers & 12 & 9 \\
\hline 5. & Swear Words & 4 & 2 \\
\hline 6. & Compound Requests & 1 & - \\
\hline 7. & Tag Questions & 3 & 1 \\
\hline 8. & Questions & 22 & 19 \\
\hline 9. & Interruptions & 4 & 1 \\
\hline 10. & Overlapping & 3 & 1 \\
\hline 11. & Talk Domination & 11 & 2 \\
\hline 12. & Silence & - & 4 \\
\hline
\end{tabular}

\section{Qualifiers}

Qualifiers were more frequently used by Gigi rather than Alex in their conversations. Alex used qualifiers 12 times, while Gigi used qualifiers 25 times. Both of them used qualifiers or hedges in order to soften their statement.

[1] Gigi: See when I said "meeting someone" I guess that was kind of a broad term, kind of a wide interpretation of the word meeting.

In example [1], Gigi used qualifiers three times in her utterance. She used the words guess and kind of to soften her statement about meeting someone. In this case, she tried to explain to Alex that women have the different interpretations of the word "meeting".

\section{Controlling the Topics}

Alex tended to control the topic more than Gigi. He controlled the topic 12 times while Gigi only eight times. In this case, Alex was the powerful speaker who can switch more topics in their conversations. 
[2] Gigi: I'm really sorry to bug you. I thought you had some really good insights and I wanted to ask you a question.

Alex: Okay, look, now I need to be harsh with you, Conor's never gonna be interested in you, Gigi.

The situation of the conversation above was Alex thought that Gigi would talk about Conor on their beginning part of their conversation. Alex directly gave his opinion about Conor when he said "Conor's never gonna be interested in you, Gigi" without asking Gigi what question she wanted to ask. In other words, Alex as a man speaker tended to switch the topic of their conversation.

\section{Verbal Fillers}

Based on the data, Pearson's (1985) theory which claims about women tend to use more verbal fillers in cross-sex conversations are not proved. Alex used verbal fillers 13 times while Gigi used verbal fillers eight times. In this case, the male character, Alex, was used more verbal fillers rather than Gigi in cross-sex conversations.

[3] Alex: Well, I'm just trying to help.

In example [3], Alex used the word well as verbal fillers in the beginning part of his utterance. $\mathrm{He}$ just wanted to help Gigi when said "...I'm just trying to help". When he still thought about his statement, he used a verbal filler in order to fill the pause in front of his utterance.

\section{Intensifiers}

The result shows that Alex frequently used more intensifiers rather than Gigi. Alex used 12 intensifiers while Gigi used nine intensifiers. They used intensifiers in order to exaggerate their emotional feeling.

[4] Alex : I had no idea it would be such a madhouse.

When Alex talked to Gigi about the situation of the party in his house, he used the intensifier such to describe the place in something specified as in example [8]. In this case, he described his house as a chaos place by using the word madhouse.

\section{Swear Words}

The researcher identified that Alex used swear words four times. It was different from Gigi where she used swear words twice in her utterances. In this case, both of them did the swearing in order to show their emotional expression.

[5] Gigi: I may do a lot of stupid shit, but I know I'm a lot closer to finding someone than you are.

Example [5] shows that Gigi also did the swearing by using the words stupid shit to express her disappointment over Alex. Gigi recognized that she had done the stupid thing to Alex but she defended herself that what she had done was still right.

\section{Compound Requests}

Alex was the only one speaker who used compound requests in his 
utterance. He used it when he tried to ask Gigi to do some things in the party like in the example [6].

[6] Alex: Listen, I gotta go make a liquor run. But it looks like the food could use some refreshing. Would you mind helping and refilling the chips?

From the example above, it shows that Alex used the words would you mind to soften his request to Gigi. By using the words would you mind Alex seemed to show his politeness to Gigi.

\section{Tag Questions}

Alex used tag questions three times while Gigi only used one tag question. The interesting part of this case is that the female character, Gigi, used fewer tag questions than the male character, Alex. In other words, Lakoff's (1975) theory that mentions women use more tag questions than man was not proved in this research. Both of them used tag questions in order to show their feeling of unsure about the things they talked about.

[7] Alex: I thought I better come up with some really great excuse to get over here. That how it's done, isn't it?

In example [7], Alex used formal tag question which seemed that he did not need a certain answer of his statement to Gigi.

\section{Questions}

The researcher analyzed that Alex asked 22 questions to Gigi in the whole of conversations. Meanwhile, Gigi asked 19 questions less than Alex.

[8] Gigi: So, what, now I'm just supposed to run from every guy who doesn't like me?

Alex: Yeah.

Gigi asked a question about herself when she faced a guy who did not like her as in example [8]. In this case, she did not really need specific information from Alex. She just wanted to make Alex responded her question in order to ensure that the conversation was still continuous.

\section{Interruptions}

The researcher identified that Gigi only interrupted Alex once. Meanwhile, Alex was the only one speaker who performed the interruptions four times. The obtained data shows that men speaker used more interruptions than women do.

[9] Gigi: He might have used some derivative of that. So, he says he's going to call, but then gave me his card and he says....

Alex: (-----interruption-----) Oh, he's not interested.

From example [9], interruptions happened when the second speaker, Alex, suggested an important message to the first speaker, Gigi. When Gigi was talking about Connor, Alex interrupted her and 
informed that what she thought about Connor was wrong. By using men's perspective, Alex tried to explain that Conor actually did not like Gigi even they had a date "Oh, he's not interested."

\section{Overlapping}

Overlapping occurs when the second speaker begins to speak when the first speaker still talks his or her last word. This case was happened in Alex and Gigi's conversations. The researcher analyzed that Alex overlapped 3 times while Gigi only once.

[10] Gigi: I don't know if you'd call it hot, I mean this guy Conor and I have only been out the one time.... Alex: ------ (overlap) -----Wait, wait, wait, Conor Barry?

In the example [10], Alex overlapped Gigi when she was talking about Conor. Alex tried to guess that Gigi was talking about Conor Barry by asking her before she completed her utterance.

\section{Talk Domination}

In line with Thorne's (1981) theory about a male speaker who tends to dominate the conversation in cross-sex conversation, the researcher identified the indication that the male speaker, Alex was an expert in the conversations.

[11] Gigi: You cannot tell from a cursory glance that he's not into her.

Alex: Actually, I can. I see this stuff going on every night. Now watch this, she's going on about her macrobiotic diet.

The example above portrays Alex as the dominant speaker. He tried to make Gigi sure about his utterance when he said, "Actually, I can. I can see stuff..." Alex, in addition, dominated the conversation when he talked about the girl they saw "Now watch this, she's...."

\section{Silence}

The researcher identified silence that occurred in the conversation was only done four times by Gigi. This case indicates that woman speaker was silent more than man speaker.

[12] Gigi: I'm Gigi. Conor and I went out last week. And I just... (silence)..I thought if I ran into him...(silence)...I don't know. I'm gonna go.

Example [12] shows that Gigi was silent when she was unsure of Alex's reaction to her comment. There was a long space before she continued to share her personal problem. When she told her feeling about Conor, she was silent again then decided to not continue her problem when said "...I don't know. I'm gonna go."

\section{The Factors of}

Misunderstanding in Alex's and Gigi's Conversations Involvement versus Independence Example [13]

Alex: I once called 55 Lauren Bell's until I got the right one.

Gigi: That's cute. What happened? 
Alex: Oh, yeah, as it turns out, her ass looked really huge in daylight.

Gigi: Is it your sensitivity that makes you so popular with women?

Alex: Don't call him. He doesn't like you.

The example above shows that the male speaker, Alex, did not want to disclose more about his personal problem. Alex tried to share his experience when he was looking for the right woman for him, and then Gigi asked what happened next. He responded to Gigi's question by continuing his story. When Gigi asked deeper about his story, Alex did not answer her question but he restated to Gigi about their previous topic "Don't call him. He doesn't like you."

Message versus Metamessage Example [14]

Alex: Would you mind helping and refilling

Gigi: (----interruption----) kind of like co-hosting?

Alex: Uhh, OK. Just refilling the chips. They're on the fridge. Thanks.

Example [14] shows that Alex asked Gigi to help him in his party. In this case, he was asking help by using polite request. For Alex, this was just an ordinary request when he stated, "Just refilling the chips" to Gigi without any hidden messages in his request. Conversely, Gigi thought that this was not an ordinary request from Alex. In other words, she focused on metamessage on Alex's request when she interrupted "...kind of like co-hosting?" because She thought that there was a signal from Alex to make both of them in a closer relationship by helping Alex in the party.

\section{Cooperative versus Competitive}

The researcher did not find any conversations which could be classified as the factor of cooperative versus competitive because when the woman character, Gigi, had a personal problem, Alex as the man character helped her by solving her problem. In other words, there was no indication of cooperative or competitive talk that led Alex and Gigi to get misunderstanding.

\section{Conclusions}

The conversational styles used by Alex, as a male character in the cross-sex conversations were qualifiers, controlling the topics, verbal fillers, intensifiers, swear words, compound requests, tag questions, questions, interruptions, overlapping, and talk domination. Meanwhile, the conversational styles used by Gigi were qualifiers, controlling the topics, verbal fillers, intensifiers, swear words, tag questions, questions, interruptions, overlapping, talk domination, and silence.

In this case, the researcher identified that Alex had the higher frequency in using controlling the topics, verbal fillers, intensifiers, swear words, compound requests, tag questions, questions, interruptions, overlapping and talk domination. 
Based on the obtained data, Alex did not use silence in the whole conversations. Gigi, on the other hand, had the higher frequency in using qualifiers and silence. In this part, the researcher did not discover any compound requests on Gigi's utterances.

The second question deals with the factors that affect the misunderstanding in Alex's and Gigi's conversations. They were involvement versus independence and message versus metamessage. The researcher identified two cases that represent involvement versus independence and two cases that represent message versus metamessage.

\section{References}

Arliss, L. P. (1991). Gender communication. Englewood Cliffs, NJ: Prentice-Hall. Coates, J. (1993). Women, men and language. London: Longman.

Gumperz, J. J. (1982). Language and social identity. Cambridge: Cambridge University Press.

Haas, A., \& Sherman, M. A. (1982). Conversational topic as a function of role and gender. Psychological Reports, 51(2), 453-454.

Lakoff, R. (1975). Language and women's place. New York: Harper \& Row.

Maltz, D., \& Borker, R. (1982). A cultural approach to male-female communication. In Gumperz, J. J. (Ed.). Language and social identity. Cambridge: Cambridge University Press.

Pearson, J. C. (1985). Gender and communication. Dubuque, IA: William C. Brown Company Publisher.

Tannen, D. (1986). That's not what I meant! New York: William Morrow and Company, Inc.

Tannen, D. (1991). You just don't understand: Women and men in conversation. London: Virago.

Tannen, D. (1995). The power of talk: Who gets heard and why. Harvard Business Review, 73(5), 138-148.

Tannen, D. (2005). Conversational style: Analyzing talk among friends. Oxford: Oxford University Press.

Thorne, B., \& Henley, N. (1975). Language and sex: Difference and dominance. Rowley, Massachusetts: Newbury House Publishers.

Tsutsui, K. (2008). Culturally and linguistically driven misunderstanding? The analysis of intercultural misunderstanding. Retrieved Mei $5^{\text {th }}, 2016$, from http://comm.louisville.edu.

Wardaugh, R. (2006). An introduction to sociolinguistics. Oxford: Blackwell.

Zimmerman, D., \& West, C. (1975). Sex roles, interruptions, and silences in conversation. In Thorne, B. \& Henley, N. (Eds.), Language and sex: Difference and dominance. Rowley, Massachusetts: Newbury House Publishers. 